\title{
Improving hypertension control among excessive alcohol drinkers: a randomised controlled trial in France
}

Thierry Lang, Viviane Nicaud, Bernadette Darné, Bernard Rueff and the members of the WALPA group

\begin{abstract}
Objectives - To improve blood pressure control among hypertensive $(>140)$ $90 \mathrm{mmHg}$ ) excessive alcohol drinkers.

Design - Fourteen worksite physicians were randomised into an intervention group and a control group. The intervention was based on training the worksite physicians and follow up of those hypertensive subjects defined as excessive drinkers. Follow up was based on self monitoring of alcohol consumption by the subject, in view of the results of their gamma glutamyl transferase (GGT) activity determination.
\end{abstract}

Setting - Fourteen workplaces in France mainly in the industrial sector.

Subjects - Altogether 15301 subjects were screened by the 14 physicians: 129 of these were included in the study.

Main outcome measures - This was the difference between the initial systolic blood pressure (SBP) and the SBP one year later $(\triangle B P)$. Secondary criteria were the difference between the initial and final diastolic blood pressure $(\triangle D B P)$ and $\triangle B P$ at two years; antihypertensive treatment; stated alcohol consumption ( $\triangle A C) ; \Delta G G T$; and body mass index ( $\triangle B M I)$.

Results - The decrease in SBP levels was significantly larger in the intervention group than in the control group: at one year, $\triangle$ SBP values were -11.9 $(15 \cdot 6) \mathrm{mmHg}$ and $-4.6(13.8)$ respectively $(p<0 \cdot 05)$. This benefit was still observed after two years of follow up $(-13 \cdot 8$ $(17 \cdot 4) \mathrm{mmHg} v-7.5(14 \cdot 2) \mathrm{mmHg}(\mathrm{p}<0.05))$. No difference was observed in DBP. The percentage of treated subjects did not differ between groups. At one year, $\triangle$ AC was larger in the intervention group $(-2 \cdot 8$ $(5 \cdot 2) \mathrm{U} / \mathrm{d})$ than in the control group $(-1 \cdot 6$ (3.4) $(p<0 \cdot 1))$. $\triangle$ GGT and $\triangle B M I$ did not differ between the two groups. A weak positive correlation was observed between $\triangle A C$ and $\triangle S B P(r=0 \cdot 16)$.

Conclusions - An intervention aimed at the hypertensive excessive drinkers in a working population was found to be effective in reducing SBP on a long term basis (two years). The mechanisms of reduction in alcohol consumption and improved drug compliance cannot be ascertained in this pragmatic study. From a public health point of view, reducing the excess cardiovascular risk among a "hard to reach" population seems feasible with a strategy specifically designed for this high risk group.

\section{(f Epidemiol Community Health 1995;49:610-616)}

A protective effect of alcohol consumption particularly wine - on cardiovascular disease has been reported in many studies. ${ }^{1}$ However, this effect was observed for moderate daily intakes. In contrast, high consumption is associated with a high incidence of coronary heart diseases, cerebral haemorrhage, and increased total mortality..$^{2-4}$ High blood pressure (BP) partly accounts for these results. Alcohol consumption has been shown to be a risk factor for high $\mathrm{BP},{ }^{5-8}$ an effect which is reversible. ${ }^{9-13}$ In addition, BP control and compliance with antihypertensive treatment were shown to be low in this group of heavy alcohol consumers. $^{81415}$ In France, mortality from cardiovascular diseases on one hand and alcohol related diseases on the other hand, is highly correlated. For instance, cerebrovascular and alcohol related mortality rates were 767 and $2160 /$ million inhabitants aged 35 to 64 years among rural workers in Brittany compared with values of 46 and 98 respectively among executives in Champagne. ${ }^{16}$ These data suggest that cardiovascular health improvement might be expected from strategies aimed at groups in the population characterised by high alcohol intakes. In a recent review, Ockene noted that despite their unusually high incidence of poor health behaviours, research examining treatment options in populations of alcohol abusers has not been done. ${ }^{17}$ There is a well known relationship between alcohol consumption and BP. ${ }^{5-13}$ Whether reducing alcohol intake on a long term basis is associated with a decrease in BP is not documented. We therefore undertook a study to test the hypothesis that an intervention at the worksite might improve BP control in a group of excessive alcohol drinkers. The basis of this intervention was to promote a reduction in alcohol intake among hypertensive subjects. This study was designed on an intention to treat basis, since heavy drinkers are unlikely to participate in preventive activities. Assessing the effectiveness on the whole population of drinkers and not only among volunteers was thus considered as an important issue.

\section{Methods}

GENERAL DESIGN

The study was a randomised trial, comparing 
an intervention and a control group. The units of randomisation were the worksite physicians. Each one was in charge of one or several companies. They were allocated to either group after they had given consent and both the managers and the personnel of the companies to be included had agreed. In France, an annual medical examination by the worksite physician is mandatory. At this visit, each physician included any subject who met the criteria for the study and gathered the data. The main outcome measure was the difference in BP between the base line at inclusion and after one year of follow up $(\triangle \mathrm{BP})$. This difference after two years of follow up was a secondary end point of the study. The other secondary criteria were the difference between initial and final $\gamma$ glutamyltransferase (GGT) activities ( $\Delta$ GGT), alcohol consumption ( $\triangle \mathrm{AC}$ ) as stated by the subject, body mass index $(\triangle \mathrm{BMI})$, the percentage of subjects currently taking antihypertensive treatment, and the frequency and length of work absenteeism for illness or accidents.

\section{INCLUSION OF WORKSITE PHYSICIANS}

These were recruited on a voluntary basis through professional networks. If they agreed to participate, they had to explain the study to the committees of the companies to be included. These committees (CHSCT: Comités d'Hygiène, de Sécurité et des Conditions de Travail) are composed of the representatives of the personnel and of the managerial staff. They deal with safety of working conditions, and health problems. Worksite physicians were randomised only after securing the agreement of these committees. In each group, the physicians included every eligible subject in the study. After randomisation, both groups of physicians received a training session on BP measurement. A written protocol was given to each physician describing the criteria for inclusion and collection of data in both groups, as well as the intervention in the intervention group. As far as BP was concerned, in both groups, a letter was sent by the worksite physician to the subject's doctor, reporting the BP measurement results. If necessary, subjects with no general practitioner were advised to make an appointment with a doctor or at the hospital.

\section{INCLUSION OF THE INDIVIDUALS}

To be eligible, a subject had to fulfil two conditions - to be hypertensive and an excessive drinker. At the first screening visit, subjects were temporarily included if their BP was over $140 / 90 \mathrm{mmHg}$ (mean of the two measurements at each visit), whether or not they were currently on antihypertensive treatment. Their GGT value was requested for a second meeting. At the second visit, one month later, these subjects were definitely included in the study if (1) their BP still fulfilled the same criteria using a random-zero (RZ) sphygmomanometer (Hawksley and Sons, Lancing, Sussex) and (2) if, additionally, the GGT value was over 1.5 times the upper limit of the normal range for the laboratory. Any subject temporarily included after the first visit who did not attend the second visit, was assumed to be an excessive drinker and was thus definitely included in the study. For the first six enrolled physicians (three in each group), the BP threshold for inclusion was $160 / 95 \mathrm{mmHg}$. It was decided to lower the level of this entry criterion to increase the number of subjects recruited. A threshold of $>140 / 90 \mathrm{mmHg}$ was defined since the intervention was based on a non-pharmacological approach. ${ }^{18}$ BP was measured twice during each visit, before and after the interview, at the right arm, in the sitting position after a 10 minute rest. The diastolic BP was defined as the Korotkoff's phase V. A bladder designed for the obese was used for each subject. ${ }^{19} \mathrm{AC}$ was not used as an entry criteria. The stated average consumption of the previous month was recorded, however, assuming that one unit is the alcohol content of a glass of beer, wine or spirit (approximately $12 \mathrm{~g}$ alcohol - given the different sizes of the glasses used for the different beverages). ${ }^{20}$

The criteria for exclusion were the following: planned departure or retirement in the next two years; diagnosis of secondary hypertension; severe liver disease (cirrhosis, alcoholic hepatitis, or alcohol related haemorrhage); a high GGT not related to alcohol (liver or pancreas tumour, chronic hepatitis, current use of oral contraceptive pill, treatment with clofibrate, barbiturics, antidepressants, anticoagulants). At the end of the follow up period, one year later, during the annual medical examination, $\mathrm{BP}$ was measured with a $\mathrm{RZ}$ manometer and the GGT was checked in the same laboratory that had done the original measurement. All subjects were informed that they were participating in a study that had been approved by the Commission Nationale Informatique et Libertés (CNIL).

\section{INTERVENTION}

The intervention was directed at both the worksite physicians and the patients. In the intervention group, training sessions for the physicians were organised before the study began and, one, three and six months afterwards. Specialists in alcohol related diseases, a consultant in legal and social aspects of alcohol at the workplace, and a psychiatrist also attended these sessions. Sharing of experiences between the physicians was an important part of these meetings. As far as the subjects were concerned, they were invited to visit the worksite physician after one, three, six, and 18 months, and on each occasion to bring the result of their GGT determination. The frequency and dates of these visits were strictly standardised and monitored, as was the performance of a GGT test. The relationship between the physician and the subject was standardised as much as possible. The subject was encouraged to find for himself the level of alcohol consumption which would lower his GGT activity to within the normal range. The goal of the intervention was not to stop alcohol intake in all subjects but to reach a moderate level of consumption, since most of 
these drinkers were not expected to be alcohol dependent. With these subjects, changing from excessive social drinking to controlled consumption is believed to be possible. ${ }^{21}$ The efficacy of this model was suggested by a study in Sweden. ${ }^{22}$ No emphasis was placed on BP, the measurement of which was not part of the protocol. Physicians in both groups were asked to measure BP at only three encounters - at inclusion and at one and two years.

Physicians in the control group were requested to continue with their current procedures, including any activity or campaign dealing with cardiovascular diseases or alcohol.

\section{DATA ANALYSIS}

To minimise any interobserver and interlaboratory variations, the difference between the initial and final values was used as the outcome measure. A one sided test was planned in the protocol, at the beginning of the study, since a possible increase in BP in the intervention group was expected to occur only as a result of chance. The analysis was performed on an intention to treat basis and thus included not only each eligible patient on the basis of BP on two different days and GGT measures, but also patients who were eligible on the basis of their first BP result but who did not attend for the second visit with the result of their GGT determination. The anticipated difference between groups for SBP, chosen as the main outcome criteria, was $6 \mathrm{mmHg}$. To test this hypothesis with a risk $\alpha=5 \%$ and a power of $90 \%$ using a one tailed test, 90 subjects per group would have been required, without taking into an account randomisation by group. This latter factor could not be ignored in the analysis because there was a physician effect on some outcome criteria. Since the sizes of the groups were different according to the physicians, it was not possible to use the means of the results for each physician. ${ }^{23}$ Mean (SD) values were therefore presented by pooling the results, as an individual randomisation. The significance of the test, however, was obtained by testing the group effect using the variance of the physician effect instead of the residual variance. ${ }^{2425}$ The nested model of analysis of variance was performed using the GLM procedure from the $S A S$ statistical software. ${ }^{26}$ The physician effect was described as a random effect, nested in the group effect. In each group, some physicians recruited few patients $(<5)$. Our hypothesis was that they might be less well trained than the other physicians both in terms of measuring BP and performing the intervention. Thus, results will be presented including and excluding those from these physicians. The means of small groups were compared using non-parametric tests (MannWhitney $U$ test). The possible effect of antihypertensive therapy was taken into account in the analysis as follows. In the case of a lack of difference in BP values between groups, an analysis of the proportion of treated patients would have been performed, with the hypothesis that the same BP levels could have been achieved with less antihypertensive treat- ment, due to the reduction in alcohol consumption. Conversely, in case of a larger reduction in the intervention group, the percentage of treated hypertensives was to be analysed in order to make a distinction between lower BP levels resulting from decreased alcohol consumption and those due to increased antihypertensive therapy.

\section{Results}

POPULATION

Nineteen occupational physicians were recruited. Six of them participated in the feasibility study: two had no subjects who met the study criteria and one had to stop for personal health reasons. Among the remaining 13 physicians, one did not have any subjects who met the study criteria and one had to stop before the beginning of the study. Fourteen randomised doctors therefore participated in the full study. A total of 15301 subjects were examined during the annual examination. Of these, 460 met the BP criteria for eligibility at the first visit. Eventually, 129 subjects met both the BP and excessive drinking criteria and were thus included in the study. The percentages of eligible subjects did not differ significantly between the two groups $(3.3 \%$ and $3.0 \%)$, nor did the proportions of subjects included $(0.8 \%$ and $0 \cdot 7 \%)$. Most subjects were men $(95 \%)$ and their mean (SD) age was 43 (7) years. Most had a low educational level and were skilled or unskilled workers (table 1). More than two thirds worked in the industrial sector. None of the subjects had cardiovascular disease. Twenty one per cent in the intervention and $18 \%$ in the control group were currently taking antihypertensive treatment. The medications were: $\beta$ blockers $(41 \%)$, converting enzyme inhibitors $(18 \%)$, diuretics $(14 \%)$, calcium inhibitors $(4 \%)$, others $(4 \%)$, more than one treatment $(14 \%)$, unknown $(9 \%)$. One of three subjects stated they had no general practitioner. The two groups did not differ significantly, except for wine consumption, which was higher in the intervention group $(p<0.05)$. Twelve per cent of the subjects in the intervention and 16 per cent in the control group were included despite their absence at the second inclusion visit.

\section{FOLLOW UP}

There were 67 subjects in the intervention and 62 in the control group. Two physicians, one in each group were responsible for a large number of these (22 in the intervention and 34 in the control group). Five physicians included fewer than five subjects (two in the intervention; three in the control group). At one year follow up, data were collected for $57(85 \%)$ of the intervention group and 59 (95\%) of the control group (NS). The thirteen subjects lost to follow up did not differ from the others with regard to age and BP. Among the 13 lost to follow up, four (two in each group) were made redundant. GGT measurements were obtained for 72 and $69 \%$ of the subjects in the intervention and control groups respectively. In the intervention group $40 \%$ had three GGT measurements. 
Table 1 Characteristics of the subjects at study inclusion*

\begin{tabular}{|c|c|c|c|c|}
\hline & $\begin{array}{l}\text { Intervention } \\
(n=67) \\
\text { Mean }\end{array}$ & $\begin{array}{l}u p \\
(S D)\end{array}$ & $\begin{array}{l}\text { Control group } \\
(n=62) \\
\text { Mean }\end{array}$ & $(S D)$ \\
\hline $\begin{array}{l}\text { Age }(\mathrm{y}) \\
\text { Body mass index }\left(\mathrm{kg} / \mathrm{m}^{2}\right) \\
\text { Cigarettes/day } \\
\text { Systolic BP }(\mathrm{mmHg}) \\
\text { Diastolic BP }(\mathrm{mmHg}) \\
\text { Heart rate } / \mathrm{mn}\end{array}$ & $\begin{array}{r}43 \cdot 7 \\
28 \cdot 2 \\
6 \cdot 5 \\
164 \cdot 5 \\
99 \cdot 9 \\
83 \cdot 8\end{array}$ & $\begin{array}{r}(6 \cdot 9) \\
(4 \cdot 6) \\
(10 \cdot 3) \\
(13 \cdot 2) \\
(10 \cdot 6) \\
(11 \cdot 0)\end{array}$ & $\begin{array}{r}42 \cdot 1 \\
26 \cdot 8 \\
9 \cdot 6 \\
161 \cdot 6 \\
98 \cdot 3 \\
82 \cdot 8\end{array}$ & $\begin{array}{l}(8 \cdot 2) \\
(5 \cdot 4) \\
(11 \cdot 5) \\
(12 \cdot 1) \\
(10 \cdot 8) \\
(14 \cdot 8)\end{array}$ \\
\hline $\begin{array}{l}\text { Stated alcohol consumption: } † \\
\text { Wine (U/d) } \\
\text { Beer (U/d) } \\
\text { Spirits (U/d) }\end{array}$ & $\begin{array}{l}5 \cdot 8 \\
1 \cdot 8 \\
0 \cdot 3\end{array}$ & $\begin{array}{l}(3.9) \\
(1.9) \\
(0.6)\end{array}$ & $\begin{array}{l}4 \cdot 0 \\
2 \cdot 0 \\
0 \cdot 8\end{array}$ & $\begin{array}{l}(2 \cdot 6) \\
(2 \cdot 5) \\
(1 \cdot 8)\end{array}$ \\
\hline $\begin{array}{l}\gamma \text { glutamyl transferase } \ddagger(\mathrm{UI}) \\
\text { Limits of lower quintile, median, and upper quintile }\end{array}$ & $\begin{array}{l}142 \cdot 4 \\
58-99-200\end{array}$ & $(134 \cdot 5)$ & $\begin{array}{l}178 \cdot 4 \\
75-113-230\end{array}$ & $(194 \cdot 3)$ \\
\hline Sex (\% men $)$ & 95 & & 95 & \\
\hline $\begin{array}{l}\text { Education level (\%) } \\
<6 \mathrm{y} \\
6-10 \mathrm{y} \\
>10 \mathrm{y}\end{array}$ & $\begin{array}{l}51 \\
35 \\
14\end{array}$ & & $\begin{array}{l}52 \\
36 \\
12\end{array}$ & \\
\hline $\begin{array}{l}\text { Absenteeism } \geq 1 \mathrm{~d}(\%) \\
\text { Illness } \\
\text { Accident }\end{array}$ & $\begin{array}{r}38 \\
3\end{array}$ & & $\begin{array}{l}33 \\
10\end{array}$ & \\
\hline $\begin{array}{l}\text { Current antihypertensive treatment (\%) } \\
\text { Stated good compliance }(\%)\end{array}$ & $\begin{array}{l}21 \\
86\end{array}$ & & $\begin{array}{l}18 \\
80\end{array}$ & \\
\hline Subjects who reported having a GP (\%) & 59 & & 74 & \\
\hline
\end{tabular}

* None of the differences between groups was statistically significant.

+ Stated alcohol consumption was obtained for 50 subjects in the intervention group and 53 in the control group.

$\ddagger$ Values were obtained for 50 subjects in the intervention group and 43 in the control group.

Fifty one per cent attended for at least two consultations. The GGT results were analysed and discussed at one consultation out of two. One subject out of three did not respond to any invitation.

After two years of follow up, 52 subjects $(78 \%)$ in the intervention group and $49(79 \%)$ in the control group were examined. Among those lost to follow up, nine had been laid off for economic reasons, six had been absent from work because of various illnesses, and one had died. In the intervention group, $46(69 \%)$ attended the visit at 18 months, $34(74 \%)$ of whom had their GGT results.

\section{OUTCOME CRITERIA}

$B P$ at one year

When the five physicians who included fewer than five patients were excluded, the reduction in SBP levels was significantly larger in the intervention compared with the control group (table 2). When the effects of randomisation

Table 2 Outcome criteria in the two groups*

\begin{tabular}{|c|c|c|c|}
\hline & \multicolumn{3}{|c|}{ Differences between start and end } \\
\hline & Intervention group & Control group & $p$ \\
\hline $\begin{array}{l}\text { No } \\
\Delta \text { Systolic BP } \\
\Delta \text { Diastolic BP } \\
\text { No } \\
\Delta \text { Heart rate } \\
\text { No } \\
\Delta \text { Body mass index } \\
\text { No } \\
\Delta \gamma \text { glutamyl transferase } \\
\text { No } \\
\Delta \text { Alcohol intake (glasses/d) } \\
\text { No } \\
\Delta \text { Absenteeism for illness }\end{array}$ & $\begin{array}{l}50 \\
-11 \cdot 9(15 \cdot 6) \\
-5 \cdot 3(9 \cdot 8) \\
50 \\
-2 \cdot 1(14 \cdot 7) \\
46 \\
0 \cdot 08(0 \cdot 87) \\
37 \\
-0 \cdot 48(2 \cdot 38) \\
41 \\
-2 \cdot 85(5 \cdot 19) \\
45 \\
-3 \cdot 80(32 \cdot 7)\end{array}$ & $\begin{array}{l}56 \\
-4 \cdot 6(13 \cdot 8) \\
-4 \cdot 6(7 \cdot 9) \\
56 \\
-3 \cdot 1(12 \cdot 9) \\
55 \\
-0 \cdot 41(4 \cdot 03) \\
31 \\
-0 \cdot 79(1 \cdot 52) \\
48 \\
-1 \cdot 56(3 \cdot 44) \\
48 \\
+5.96(37 \cdot 19)\end{array}$ & $\begin{array}{l}<0.01 \dagger \\
\text { NS } \\
\text { NS } \\
\text { NS } \\
\text { NS } \\
=0.09 \dagger \\
\text { NSS }\end{array}$ \\
\hline
\end{tabular}

* Physicians who included $<5$ subjects were not included in this table. † One sided Student's $t$ test.

$\ddagger$ Ratio between GTT value and upper normal limit of the laboratory.

f Wilcoxon non-parametric test. by group were taken into an account, the difference was significant $(p=0 \cdot 03)$. Including those physicians with a very small sample size did not change the results: $\triangle S B P$ was -11.5 $(15.2) \mathrm{mmHg}$ in the intervention group and $-6.0(15.7) \mathrm{mmHg}$ in the control group $(p<0.05)$. The largest benefit was achieved in the group of physicians who included from five to 10 subjects: $-16.2(18.4) \mathrm{mmHg} v-1.4$ $(14.9) \mathrm{mmHg}$ in the groups respectively $(\mathrm{p}<0.01)$. No difference was observed concerning DBP. There was a tendency for subjects taking antihypertensive treatment at the beginning of the study, to have a greater $\triangle \mathrm{SBP}$ in the intervention group $(-17 \cdot 5(19 \cdot 1) \mathrm{mmHg}$, $\mathrm{n}=10)$ than in the control group $(-1 \cdot 7$ (6.7) $\mathrm{mmHg}, \mathrm{n}=9$ ) (NS).

There was also a larger $\triangle S B P$ in the intervention group $(-11.0(18.7) \mathrm{mmHg}, \mathrm{n}=$ 13) than in the control group $(+1.8$ $(12.4) \mathrm{mmHg}, \mathrm{n}=19)$ in subjects who had no GGT result at inclusion. Twenty one per cent of the patients in the intervention group and $18 \%$ in the control group were currently taking antihypertensive treatment at the beginning of the study (NS). In both groups, two patients stopped antihypertensive treatment and six began it during the study. The pattern of antihypertensive medications did not change significantly during the study.

\section{$B P$ after two years}

Across the entire sample of physicians, $\triangle S B P$ was $-14.0(16.6) \mathrm{mmHg}$ in the intervention group and $-7 \cdot 4(14 \cdot 1) \mathrm{mmHg}$ in the control group ( $p<0.05)$ (figure). When the five physicians who had included fewer than five patients were excluded, the decrease in SBP levels remained significantly larger in the intervention group than the control group (table 3 ). 

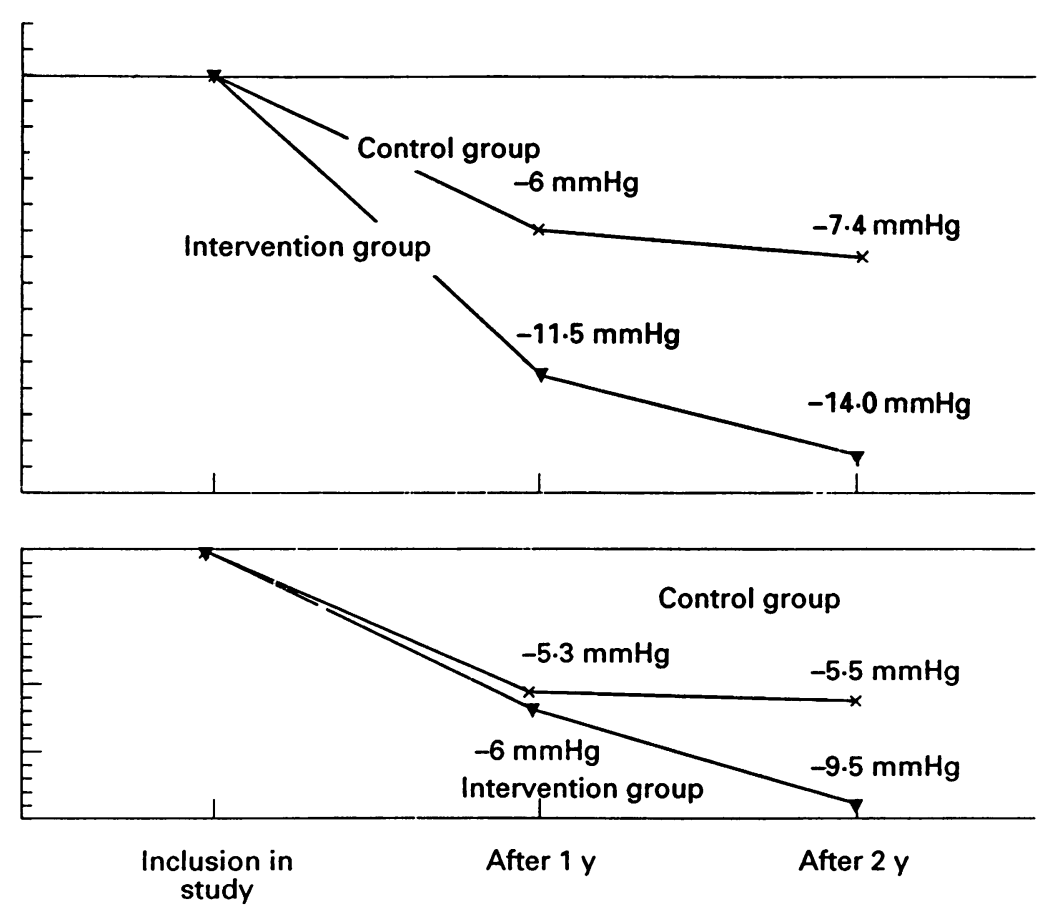

Time

Blood pressure results after one and two years of follow up. Upper panel=systolic blood pressure, lower panel diastolic blood pressure

Table 3 Results after two years of follow up*

\begin{tabular}{lccc}
\hline & \multicolumn{2}{l}{ Differences between start and end } & \\
\cline { 2 - 4 } & Intervention group & Control group & $p$ \\
\hline No* & 45 & 48 & \\
$\Delta$ Systolic BP & $-13.8(17.4)$ & $-7.5(14 \cdot 2)$ & $<0.05 \dagger$ \\
$\Delta$ Diastolic BP & $-7.3(11.9)$ & $-5.6(9 \cdot 2)$ & NS \\
\hline
\end{tabular}

* Physicians who included $<5$ subjects were not included in this table.

† One sided Student's $t$ test.
Absenteeism

The frequency and total duration of absenteeism, for both illnesses and accidents did not differ statistically between the two groups at one or two years.

\section{Discussion}

The main result of the study was the feasibility and the effectiveness of a strategy concerning a population group at high risk for complications of hypertension. SBP was reduced by $12 \mathrm{mmHg}$ in the intervention group compared with $5 \mathrm{mmHg}$ in the control group after a one year follow up. This difference persisted after two years and was even slightly more pronounced for SBP, with a tendency in the same direction for DBP. This result includes both the heavy drinkers who were compliant with the intervention and those who did not attend. The intention to treat analysis was an important issue since excessive alcohol drinkers are unlikely to volunteer for epidemiological and clinical research. In addition, a high drop out rate is to be expected. Reduction of alcohol intake has been shown to cause a drop in $\mathrm{BP},{ }^{9-11}$ but this result has been observed in volunteers over relatively short periods of time. Our study brings additional results. Firstly, it suggests the possibility of reducing high BP on a long term basis (two years) and, secondly, it proves the feasibility of obtaining this result in a whole group of heavy drinkers, not just in a subgroup of volunteers. For this reason, the setting of the study was the worksite. In France, an annual medical examination by the worksite physician is mandatory. For some groups of the population, it is the only contact with a health professional: this is all the more true if these groups are underprivileged. ${ }^{27}$

Some methodological aspects should be discussed. As anticipated, some of the subjects did not bring their GGT results or did not state their alcohol consumption. The follow up rate was high, however, as far as the main outcome was concerned. The lack of power of the study has several origins. Heavy drinking was indicated by high GGT levels, but the sensitivity of this is low. ${ }^{28}$ In addition, measurement of BP using a $\mathrm{RZ}$ sphygmomanometer has been shown to underestimate BP levels. ${ }^{29}$ As a consequence, the number of subjects included per company was much lower than expected. BP measurement, alcohol intake, and GGT are three variables characterised by high intraindividual and measurement error variances.$^{28}$ Because of the multiple working sites involved, interobserver and interlaboratory variances were added, thus reducing statistical power. However, using the differences between the final and initial BP and GGT values reduces this source of bias. In addition, the control group was not free from intervention. The physicians had to inform the staff of the company and had to make an effort to persuade people to come for a second visit - with a GGT result if they had high BP. This process, per se, is a slight intervention in terms of alcohol consumption and BP. Lastly, most of the physicians involved were concerned about excessive 
alcohol drinking and almost all of them had tried to do something about it in the past. Thus, some intervention did occur in the control group. The levels of activity in terms of alcohol management in the control group were not, however, monitored quantitatively.

A reduction in BP was observed. Could this be related to a "white coat effect"? ${ }^{30}$ A correlation was observed between the number of visits to the occupational physician - which was the hypothesis of the study - but not with the number of visits to the general practitioner. The number of BP measurements was not different between the two groups, since the visits in the intervention group did not require BP measurements. In addition, the heart rate and changes between study inclusion and the final examination did not differ between the two groups. Furthermore, the weak correlation between the reduction in BP and alcohol consumption suggests that the latter might be at least partly responsible for the reduction in BP. It thus seems unlikely that the white coat effect is entirely responsible for the result observed. The consistency of the results after two years follow up is a last argument for the causal effect of a reduction in alcohol consumption. It is, however, surprising that the only reduction observed was a reduction in BP, whereas only a tendency for a decrease in alcohol intake and no effect from GGT were observed. One could hypothesise that the effect on $\mathrm{BP}$ is independent of alcohol consumption. An increase in the number of treated subjects can be ruled out. However, therapeutic control might be improved through increased compliance with drug treatment. From our data, the stated compliance did not change throughout the study. This is, in fact, a poor measure of the true compliance. If this mechanism is involved, which was one of our expectations, it would only be part of the effect since BP decreased in both treated and untreated patients in the intervention group compared with the control group.

The stated alcohol consumption was slightly reduced during the study in the intervention group. This measure has been shown to be impaired by great intraindividual variability and bias that results in underevaluation of the true intake. The same criticisms, large intraindividual variability and poor sensitivity apply to GGT too. ${ }^{28}$ In addition, this indicator may be relatively insensitive to slight reductions in alcohol consumption. Using the CAGE questionnaire, a much better screening test, ${ }^{31}$ was not possible given the unblinded status of the worksite physicians. Thus, a true, although moderate decrease in alcohol intake resulting in a lower BP might be involved. The BP level might therefore seem to be a sensitive surrogate indicator to evaluate interventions in alcoholism prevention. Indeed, the measurement of alcohol intake is very difficult, with large intraindividual and measurement error variances leading to a lack of power. This is all the more true with GGT activities, which have low diagnostic value for excessive drinking ${ }^{28}$ and are probably even less valuable for reflecting slight changes in alcohol consumption. The multiple determinants of longitudinal changes in GGT levels and the weakness of the association with alcohol variables has been underlined in a seven year longitudinal study. ${ }^{32}$ In short term trials, ${ }^{9-13}$ as well as in studies dealing primarily with alcohol consumption, ${ }^{33}$ a decrease in BP was observed. This physiological measure might thus be a useful indicator of changes in alcohol consumption, easy to measure and independant of the observer, when evaluating the effectiveness of strategies to reduce drinking.

The predominant effect on SBP and the lack of effect on diastolic BP agrees with previous reports emphasising a closer relationship, ${ }^{7}$ sometimes exclusive, ${ }^{10}$ of alcohol intake with SBP. A closer correlation between alcohol and GGT was found in both groups at the end of the study compared with the beginning. It is worth observing that this improvement was much larger in the intervention than the control group, suggesting that an effect of the intervention was to induce more accurate measurement of alcohol consumption by the drinkers, or to improve the quality of the relationship between the doctor and the patient, or both. Although the same tendency was observed whatever the subgroup of physicians considered, the largest effect in reducing BP was obtained by the physicians who included between five and 10 subjects. Both results emphasise the importance and the effectiveness of the doctor-patient relationship in such a strategy.

The effectiveness and cost effectiveness of worksite intervention programmes has been shown. ${ }^{34}$ Our study extends the effectiveness of this approach when "hard to reach" populations - heavy drinkers in our study - are the target of the intervention. As far as the alcohol problem is concerned, our results agree with those of Wallace with general practitioners. ${ }^{32}$ In this study, a simple intervention proved to be successful on stated alcohol consumption, BP, and to a lesser extent GGT. Another study reported an effect on stated alcohol consumption, ${ }^{35}$ but the subjects lost to follow up were numerous (35\%). Two other studies failed to reduce alcohol consumption in heavy drinkers. ${ }^{3637}$ The subjects we included were heavier drinkers than in the other studies, in none of which were GGT activities over $52 \mathrm{UI} / \mathrm{l}$. The mean was over $140 \mathrm{IU} / 1$ in our population. Despite the enormous difficulties to face in this field, prevention of alcoholism through a reduction in the consumption of heavy drinkers before the occurrence of dependency, seems to be a promising research direction.

\section{Conclusion}

An intervention aimed at the hypertensive excessive drinkers in a working population was found to be effective in reducing SBP on the long term. The mechanisms - reduction in alcohol consumption and improved antihypertensive drug compliance - cannot be ascertained in this pragmatic study. However, the small number of treated antihypertensive in 
this study, as well as the results of other trials, ${ }^{913}$ suggest that a reduction in alcohol consumption accounts partly for this result. From a public health point of view, it seems feasible to reduce the excess cardiovascular risk among a "hard to reach" population, with a strategy specifically designed for this high risk group. The difference obtained with this strategy is comparable to that obtained through drug treatment in randomised drug trials. ${ }^{38}$

Worksite physicians of the WALPA working group: Drs JeanLouis Arnaudin, Annie Bertrand, Catherine Blancher, Miche Dessery, Guy Duval-Arnould, Martine Franck-Cotinat, Yves Garcier, Andre Guyon, Ellen Imbernon, Annie Le Foll, MarieGarcier, André Guyon, Ellen Imbernon, Annie Le Foll, MarieChristine Langlet, Line Le Toulouzan, Anne-Marie Martin,
Huguette Martinez, Martine Mauduit, Jean-Marie Olivier, Michelle Pellegrin, Joëlle Penalba, Catherine Raffaittin-Bodin, Christine Roitg, Patrice de Roll, Pascal Saint Eve.

We acknowledge the help of the personnel staff, the nurses, and the managerial staff of the companies who agreed to participate
in the study. Some of them provided technical and financial in the study. Some of them provided technical and financial
support. Drs François Cambien, Jean Marie Goehrs, Paul Honsupport. Drs François Cambien, Jean Marie Goehrs, Paul Honnet, Pierre Lombrail, Patrice Rioux, Alain Tugayé, and Cécile
du Temple helped us to organize the study. We thank Pierre du Temple helped us to organize the study. We thank Pierre
Ducimetière for his advice in analysing the data, Pierre Yves Ducimetière for his advice in analysing the data, Pierre Yves
Scarabin for helpful comments and Annie Bingham for reScarabin for helpful comments and Annie Bingham for reviewing the manuscript. Dr Marie-Line Thouzé and Mr Gilles of the physicians. The study was funded by the Fondation de France, the association "Recherche et Partage" and INSERM.

1 Marmot M, Brunner E. Alcohol and cardiovascular disease: the status of the U shaped curve. BMF 1991;303:565-8.

2 Donahue RP, Abbott RD, Reed DM, et al. Alcohol and hemorrhagic stroke. The Honolulu heart program. $¥ A M A$ 1986;255:2311-4.

3 Ducimetière $\mathrm{P}$, Richard $\mathrm{JL}$, Claude $\mathrm{JR}$, et al. Les cardiopathies ischémiques. Incidence et facteurs de risque. In: L'étude prospective parisienne. Paris: INSERM, 1980.

4 Dyer AR, Stamler J, Paul Oglesby et al. Alcohol consumption, cardiovascular risk factors and mortality in two Chicago epidemiologic studies. Circulation 1977;56 $1067-74$.

5 The Intersalt Co-operative Research Group. Sodium, potassium, body mass, alcohol and blood pressure. $\mathscr{f} H y-$ pertension 1988;6:S584-6.

6 Klatsky AL, Friedman GD, Armstrong MA. The relationships between alcoholic beverage use and other traits to blood pressure: a new Kaiser Permanente study. Circulation 1986;73:628-36.

7 Klatsky AL. Alcohol and blood pressure. In: Laragh JH, Brenner BM, eds. Hypertension: Pathophysiology, diagnosis,
and treatment. New York: Raven Press, 1990;277-94.

8 Lang T, Degoulet P, Aimé F, et al. Relationship between alcohol consumption and hypertension prevalence and control in a French population. 7 Chron Dis 1987;40: 713-20.

9 Potter JF, Beevers DG. Pressor effect of alcohol in hypertension. Lancet 1984;1:119-22.

10 Puddey IB, Beilin LJ, Vandongen R, et al. Evidence for a direct effect of alcohol consumption on blood pressure in normotensive men. A randomized controlled trial. $H y$ pertension 1985;7:707-13.

11 Puddey IB, Beilin LJ, Vandongen R. Regular alcohol use raises blood pressure in treated hypertensive subjects. A randomized controlled trial. Lancet 1987;i:647-651.

12 Maheswaran R, Beevers M, Beevers DG. Effectiveness of advice to reduce alcohol consumption in hypertensive patients. Hypertension 1992;19:79-84.

13 Parker M, Puddey IB, Beilin LJ, et al. Two way factorial study of alcohol and salt restriction in treated hypertensive study of alcohol and salt restriction in
men. Hypertension 1990;16:398-406.

14 Tuomilehto J, Enlun H, Salonen JT, et al. Alcohol, patient compliance and blood pressure control in hypertensive patients. Scand $\mathcal{F}$ Soc Med 1984;12:177-81.

15 Henningsen NC, Mattiasson, Ohlsson I, et al. Hypertension, levels of serum gamma glutamyl transpeptidase and degree of blood pressure control in middle-aged males. Acta Med Scand 1980;207:245-51.

16 Lang T, Cambien F, Richard JL, et al. Mortalité par maladies cérébro-vasculaires et par alcoolisme en France. Presse Med 1987;16:1351-4

17 Ockene JK, Ockene IS. Helping patients to reduce their for coronary heart disease: an overview. In: Ockene IS, Ockene JK, eds. Prevention of coronary heart disease. Boston: Little, BK, eds. Prevention of coronary hea

18 Guidelines Subcommittee. 1993 Guidelines for the management of mild hypertension: memorandum from a World Health Organization/International Society of $\mathrm{Hy}-$ pertension meeting. $\mathcal{f}$ Hypertension 1993;11:905-18.

19 Croft PR, Cruikshank JK. Blood pressure measurement in adults: large cuffs for all? $\mathcal{F}$ Epidemiol Community Health 1990;44:170-73.

20 Marmot MG. Alcohol and coronary heart disease: the status of the U shaped curve. Int $\mathcal{F}$ Epidemiol 1984;13:160-7.

21 Van Dijk WK. Alcoholism, a many sided problem. Advances in Biological Psychiatry 1979;3:2-10.

22 Kristenson $\mathrm{H}$, Ohlin H, Hulten-Nosslin MB, et al. Identification and intervention of heavy drinking in middleaged men: results and follow-up of 24-60 months of long term study with randomized controls. Alcoholism: Clin Exp Res 1983;7:203-9.

23 Cambien F, Richard JL, Jacqueson A, et al. Analyse des résultats d'un essai où des groupes ont été randomisés, resultats d'un essai où des groupes ont

24 Donner A, Donald A. Analysis of data arising from a stratified design with the cluster as unit of randomization. Stat Med 1987;6:43-52.

25 Koepsell TD, Martin DC, Diehr PH, et al. Data analysis and sample issues in evaluations of community-based health promotion and disease prevention programs: a mixed-model analysis of variance approach. 7 Clin Epidemiol 1991;44:701-13.

26 SAS Institute. SAS/STAT user's guide. Version 6, 4th ed. Cary, NC: SAS Institute Inc, $1989 ; 846$.

27 Fouriaud C, Jacquinet-Salord MC, Mahé I, et al. Médecine du travail et prévention générale. Résultats d'une enquête épidémiologique auprès de 8203 salariés. Arch Mal Prof 1991;52:333-37.

$28 \mathrm{Crabb}$ DW. Biological markers for increased risk of alcoholism and for quantitation of alcohol consumption. $f$ Clin Invest 1990;85:311-5.

29 Parker D, Liu K, Dyer AR, et al. A comparison of the random-zero and standard mercury sphygmomanometers. Hypertension 1988;11:269-72.

30 Mancia G, Bertinieri G, Grassi G, et al. Effects of blood pressure measurement by the doctor on patient's blood pressure and heart rate. Lancet 1983;ii:695-98.

31 Bush B, Shaw S, Cleary P, et al. Screening for alcohol abuse using the CAGE questionnaire. Am $\mathcal{F}$ Med 1987; 82:231-235.

32 Nilssen $\mathrm{O}$, Forde $\mathrm{OH}$. Seven-year longitudinal population study of change in gamma-glutamyl-transferase: the Tromso study. Am $\mathcal{f}$ Epidemiol 1994;139:787-92.

33 Wallace $P$, Cutler S, Haines A. Randomized controlled trial of general practitioner intervention in patients with excessive alcohol consumption. $B M \mathcal{F}$ 1988;297:663-8.

34 Foote A, Erfurt JC. The benefit to cost ratio of worksite blood pressure control programs. $¥ A M A$ 1991;265: site blood $1283-86$

35 Anderson P, Scott E. The effect of general practitioner's advice to heavy drinking men. $B r \mathcal{F}$ Addict 1992;87:891900

36 Heather N, Campion PD, Neville RG, et al. Evaluation of a controlled drinking minimal intervention for problem drinkers in general practice (the DRAMS scheme). $\mathcal{F} R$ Coll Gen Pract 1987;37:358-63.

37 Scott E, Anderson P. Randomized controlled trial of general practitioner intervention in women with excessive alcohol consumption. Drug Alcohol Revues 1990;10:313-21.

38 Collins R, Peto R, MacMahon S, et al. Blood pressure, stroke, and coronary heart disease. Part 2, short-term reductions in blood pressure: overview of randomised drug trials in their epidemiological context. Lancet 1990;335: 827-38. 